\title{
Análise espacial do uso e cobertura das terras no município de São Gabriel-Bahia, 2007 e 2018
}

Em escala Global, as mudanças no uso da terra e na cobertura vegetal estão ocorrendo de forma acelerada. No Brasil, o processo de exploração agropecuária constitui a maior força de alteração no Uso e Cobertura das Terras, realidade não diferente na região semiárida, onde se localiza o município de São Gabriel, área onde foi desenvolvida essa pesquisa, caracterizada por intenso uso dos recursos naturais. Diante disso, o objetivo do estudo foi analisar as mudanças no Uso e Cobertura das Terras no município de São Gabriel entre os anos de 2007 e 2018. Para tanto, algumas etapas foram desenvolvidas, como: construção de um banco de dados em ambiente SIG, dados vetoriais e raster, georeferenciamento de poços tubulares, Processamento Digital de Imagens (PDI), sendo utilizadas imagens de satélite TM/Landsat-5 e OLI/Landsat-8, e realizou-se a classificação supervisionada por região das mesmas, gerando os mapas de Uso e Cobertura das Terras para o período supracitado. Realizou-se trabalho de campo para a validação da classificação com o método da Exatidão Global. Os resultados apontam que a modernização da agricultura de sequeiro alcançou altos índices de produtividade entre as décadas de 1970 e 1980 , mas em contrapartida potencializou o desmatamento da vegetação de caatinga e aumentou o solo exposto com estágio avançado de degradação, provocando perca de produtividade nesse setor agrícola. A partir de então, os cultivos irrigados tornam-se frequentes, o que tem levado a um aumento na perfuração de poços tubulares, ampliando as áreas irrigadas. A pesquisa mostrou as mudanças ocorridas entre os anos de 2007 e 2018: aumento de 1,65\% da Agricultura Irrigada, e redução da Cobertura Vegetal em $-0,8 \%$, e Agropecuária-Solo Exposto em - $1,1 \%$. Corpos D’Água, Afloramento Rochoso e Área Construída aumentaram suas áreas em 0,08, 0,1 e 0,25 \%, respectivamente. Os trabalhos de campo, conjugados às análises dos dados gerados da classificação das imagens, possibilitaram concluir que a agricultura de sequeiro e a pastagem ainda configuram como sendo o principal meio de alteração da vegetação de caatinga na área de estudo, mostrando que essa supressão da cobertura vegetal ao longo dos anos tende a contribuir com o escoamento superficial das águas e redução da capacidade de infiltração do solo, aumentando os processos erosivos, principalmente nas encostas no vale do Rio Jacaré e no planalto cárstico da Sub-bacia do Baixão de Gabriel, provocando o assoreamento dos canais de drenagem.

\section{Spatial analysis of land use and land cover in the municipality of São Gabriel-Bahia, 2007 and 2018}

\begin{abstract}
On a global scale, changes in land use and vegetation cover are happening very fast. In Brazil, the agricultural exploration process constitutes the greatest force of change in Land Use and Land Cover, a reality no different in the semi-arid region, where the municipality of São Gabriel is located, an area where this research was developed, characterized by intense use of resources natural. Therefore, the objective of the study was to analyze the changes in Land Use and Land Cover in the city of São Gabriel between 2007 and 2018. For that, some steps were developed, such as: construction of a database in a GIS environment, vector and raster data, georeferencing of tubular wells, Digital Image Processing (PDI), using TM/Landsat-5 and OLI/Landsat-8 satellite images, and supervised classification by region, generating maps of Land Use and Land Cover for the aforementioned period. Field work was carried out to validate the classification using the Global Accuracy method. The results show that the modernization of rainfed agriculture reached high productivity rates between the 1970s and 1980s, but on the other hand it increased the deforestation of the caatinga vegetation and increased the exposed soil with an advanced stage of degradation, causing a loss of productivity in this agricultural sector. Since then, irrigated crops have become frequent, which has led to an increase in the drilling of tubular wells, expanding the irrigated areas. The survey showed the changes that happened between 2007 and 2018: an increase of 1.65\% in Irrigated Agriculture, and a reduction in Vegetal Coverage by $0.8 \%$, and Agriculture-Exposed Soil by $-1.1 \%$. Water Bodies, Rocky Outcrop and Built-up Area increased their areas by $0.08,0.1$ and $0.25 \%$, respectively. The fieldwork, combined with the analysis of the data generated from the classification of the images, it was possible to conclude that rainfed agriculture and pasture are still the main means of altering the caatinga vegetation in the study area, showing that this suppression of coverage over the years tends to contribute to the surface runoff of water and reduction of the soil infiltration capacity, increasing the erosion processes, mainly on the slopes of the Jacare River valley and in the karstic plateau of the Baixão de Gabriel Sub-basin, causing siltation of drainage channels.
\end{abstract}

Keywords: Geotechnologies; Irrigated agriculture; Caatinga.

Topic: Tecnologia, Modelagem e Geoprocessamento

Received: 06/07/2021 Approved: 29/07/2021

Reviewed anonymously in the process of blind peer.

Fagne Batista de Abreu (iD)

Universidade Estadual de Feira de Santana, Brasil

http://lattes.cnpq.br/9502097129012782

http://orcid.org/0000-0001-8713-7461

fagneabreu@hotmail.com

Elane Fiúza Borges (id

Universidade Estadual de Feira de Santana, Brasil

http://lattes.cnpq.br/6258771936396884

http://orcid.org/0000-0003-3871-7448

elaneborges@gmail.com

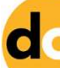

DOI: 10.6008/CBPC2179-6858.2021.007.0046
Referencing this:

ABREU, F. B.; BORGES, E. F.. Análise espacial do uso e cobertura das terras no município de São Gabriel-Bahia, 2007 e 2018. Revista Ibero Americana de Ciências Ambientais, v.12, n.7, p.535-548, 2021. DOI: http://doi.org/10.6008/CBPC2179-6858.2021.007.0046 


\section{INTRODUÇÃO}

Em escala global, as mudanças nos padrões de uso da terra e na cobertura vegetal estão ocorrendo em passos acelerados. No Brasil, o processo de exploração agropecuária constitui a mais forte força de alteração nas formas de Uso e Cobertura das Terras (BENEDETTI, 2006). A região semiárida brasileira é caracterizada por um intenso uso dos recursos naturais, ocasionado, sobretudo, pela agropecuária, devido ser a principal atividade socioeconômica da região. As características de semiaridez condicionam as populações ao desenvolvimento dessa atividade, muitas vezes sem planejamento, o que tem levado a degradação das terras e a perda da produtividade agrícola em alguns locais (TEIXEIRA, 2010).

Nesse contexto de mudanças, o estudo sobre o Uso e Cobertura das Terras torna-se de grande relevância, visto que comporta análise e mapeamentos de grande utilidade para o conhecimento atualizado das formas de Uso e Cobertura das Terras, constituindo importante ferramenta de planejamento do território. Além disso, fornece subsídios importantes para as análises e avaliações das transformações das paisagens, como as provenientes dos desmatamentos, da perda da biodiversidade e das mudanças climáticas (IBGE, 2013). Em uma escala regional e local, evidencia os efeitos do uso desordenado da cobertura das terras, como os processos de erosão acelerada, as inundações, os assoreamentos desenfreados dos rios, riachos, lagos e reservatórios (PRADO, 2004).

O Município de São Gabriel-BA, com a modernização dos processos produtivos implantados a partir de 1970 com a disponibilização de recursos financeiros aos agricultores para a compra de tratores, implementos e insumos, alcançou altos índices de produtividade relativos aos cultivos de sequeiro entre as décadas de 1970 e 1980. Em contrapartida essa modernização potencializou o desmatamento da vegetação de caatinga, principalmente para a expansão da monocultura do feijão (MACHADO, 2004; PEREIRA et al., 2013; NEPOMUCENO, 2014). O cultivo do feijão foi o principal indutor das modificações no uso e cobertura das terras na área de estudo, o que aliado a um sistema de manejo agrícola inadequado, aumento de solo exposto e com estágio avançado de degradação tem provocado uma perda de produtividade agrícola (ROCHA NETO et al., 2020). Inclui-se a isso a semiaridez regional, com anos subsequentes de irregularidades pluviométricas (BARBOSA, 2000).

Na década de 1990 iniciou a decadência dos cultivos de sequeiro. A partir de então, os cultivos irrigados passam a ser frequentes na área de estudo, tornando uma alternativa viável para os agricultores locais. Nesse contexto surgiu outra modalidade técnica, o custeio de projetos de irrigação (MACHADO, 2004; OLIVEIRA, 2015). Diante dessa realidade, a perfuração de poços tubulares e compra de kits de irrigação proporcionaram a ampliação das áreas irrigadas nos últimos anos, com uso intensivo das águas subterrâneas (RAMOS et al., 2007). A ocorrência de períodos secos prolongados, irregularidade e má distribuição espacial das precipitações, com média anual entre 500 e $600 \mathrm{~mm} / \mathrm{ano}$, têm reduzido os cultivos de sequeiro no município de São Gabriel, em contrapartida tem ocorrido uma ampliação das áreas com cultivos irrigados que pode estar aumentando a demanda por água subterrânea com consequente aumento do número de poços perfurados. Associada às características físicas de semiaridez, as águas subterrâneas desempenham 
um papel fundamental, possibilitando o uso na agricultura irrigada, surgindo como uma alternativa nos períodos de estiagem.

Com isso, este trabalho tem como questão central, compreender a relação que se estabelece entre o crescimento da agricultura irrigada, o aumento da abertura de poços tubulares e as mudanças no uso e Cobertura das Terras no município de São Gabriel entre os anos de 2007 e 2018. Sendo assim, este trabalho objetivou identificar e analisar as modificações ocorridas na paisagem local, resultante do Uso e Cobertura das Terras nos períodos de auge e decadência da agricultura de sequeiro, assim como mapear os poços tubulares e correlacioná-los com a expansão da agricultura irrigada na área de estudo nos últimos anos.

Entende-se a importância desse trabalho, devido constatar que ainda há escassez de estudos sobre as alterações no Uso e na Cobertura das Terras na região semiárida, como também sobre o avanço da agricultura irrigada e sua relação com o aproveitamento dos recursos hídricos subterrâneos, substancialmente na área em estudo.

\section{METODOLOGIA}

\section{A área de Estudo}

O município de São Gabriel localiza-se entre as coordenadas UTM (Universal Transversa de Mercator), fuso 24-S, 186059-X e 8757152-Y no Território de identidade Irecê, porção centro-norte do Estado da Bahia e possui uma área territorial de 1.146,54 km² (Figura 1).

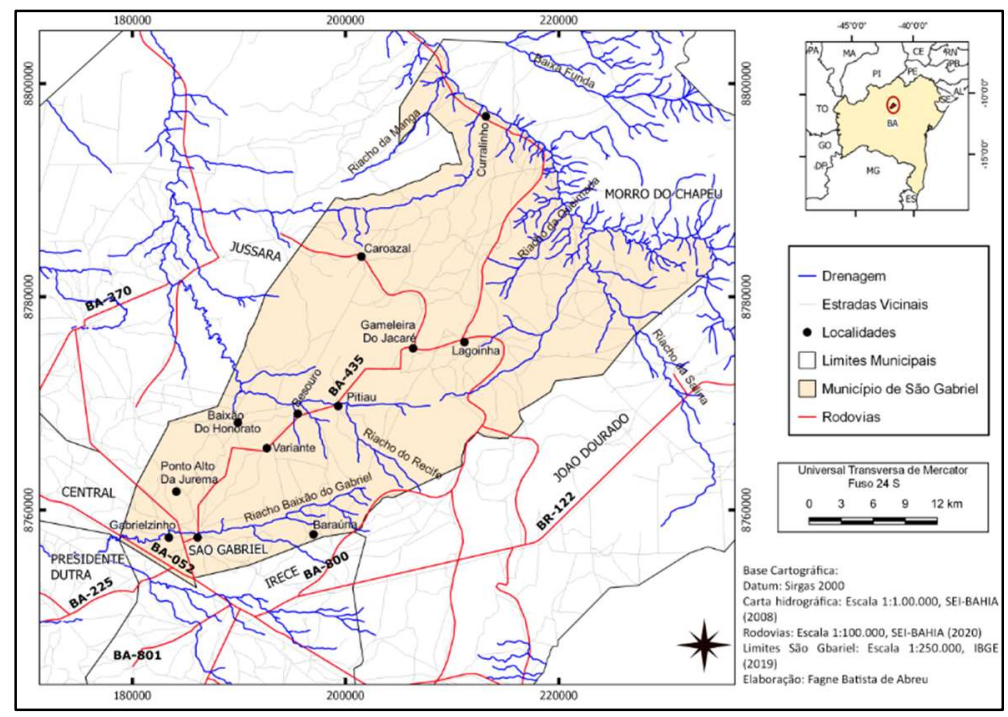

Figura 1: Mapa de localização do município de São Gabriel-BA.

Por estar totalmente inserido em uma região semiárida, segundo a tipologia climática de KOOPEN e a distribuição climática na Bahia (SEI, 1998) o clima no município de São Gabriel é do tipo BSh - Clima Semiárido quente, caracterizado por escassez de chuvas e grande irregularidade em sua distribuição. A vegetação nativa é a caatinga, composta por fitofisionomias, de porte herbáceo, arbustivo ou arbóreo, podendo ser aberta ou densa, decídua na estação seca, e verde na estação chuvosa. A rede de drenagem apresenta-se pouco densa. A área situa-se nos domínios das bacias hidrográficas dos rios Verde e Jacaré, afluentes da margem direita do rio São Francisco. Nesses domínios de calcário a rede de drenagem é 
extremamente rarefeita.

Geologicamente a área está inserida no Supergrupo São Francisco, Grupo Una que se divide nas formações bebedouro, de natureza essencialmente glacial e Salitre representada pela plataforma carbonática (BAHIA, 2015). Em relação à geomorfologia, encontra-se totalmente inserido em um planalto cárstico, em altitudes que variam de 600 a 800 metros. Caracteriza-se por uma topografia levemente ondulada, com elevações suaves (GUERRA, 1986; BAHIA, 2015). Segundo a classificação dos tipos de solos do Brasil (EMBRAPA, 2018) e a distribuição cartográfica dos solos da Bahia (SEI, 2001), predominam na área de estudo os Cambissolos Háplico eutrófico, solos pedogeneticamente pouco desenvolvidos, rasos e bem drenados, que guardam nos seus horizontes vestígios do material de origem. Apresentam uma boa fertilidade natural.

São Gabriel tem como principal atividade econômica, as atividades primárias, com destaque para a agricultura de sequeiro, com o cultivo do milho, mamona e feijão, além da pecuária bovina, suína e caprina em pequenas e médias propriedades. Todavia, nos últimos anos as terras do município de São Gabriel têm sido submetidas a alterações, fato esse que se deve basicamente a expansão da agricultura irrigada.

\section{Imagens de Satélites utilizadas no trabalho}

Nesse estudo foram utilizadas as imagens de satélites das séries TM/Landsat-5 (Thematic Mapper), órbita/ponto 218/68, referente ao ano de 2007, com data de passagem correspondente ao mês de julho e OLI/Landsat-8 (Operational Land Imager), órbita/ponto 218/68, de 2018, data da passagem no mês de dezembro. Ambas as cenas recobrem a área de estudo. A aquisição das imagens se deu a partir do sítio eletrônico do Instituto Nacional de Pesquisas Espaciais (INPE).

Quadro 1: Imagens utilizadas no estudo.

\begin{tabular}{|l|l|l|l|l|}
\hline Satélite & Data & Sensor & Orbita/ponto & Resolução \\
\hline Landsat-5 & $24 / 07 / 2007$ & TM & $218 / 68$ & $30 \mathrm{~m}$ \\
\hline Landsat-8 & $02 / 12 / 2018$ & OLI & $218 / 68$ & $30 \mathrm{~m}$ \\
\hline
\end{tabular}

\section{Processamento Digital de Imagens (PDI)}

A primeira etapa dessa pesquisa consistiu no pré-processamento, na qual foram desenvolvidas técnicas para melhorar a qualidade das imagens, e facilitar o processo de identificação e interpretação dos alvos. Realizou-se a correção atmosférica de todas as bandas das imagens, com o Plugin Semi Automatic Classification no QGIS 3.10.8. Em seguida, foi realizada a reprojeção de todas as bandas do OLI/Landsat-8, para o Hemisfério Sul, zona 24, sistema de referência geodésico Sirgas 2000. Posteriormente, as bandas das imagens LANDSAT foram integradas e aplicados o recorte da área de interesse utilizando os limites do Município de São Gabriel, escala de 1:250.000 do ano de 2019 disponibilizado pelo IBGE.

A segunda etapa correspondeu ao Processamento propriamente dito, no qual as imagens foram classificadas por meio de algoritmo automático, denominado de Classificação Supervisionada por Regiões. Esse método requer reconhecimento prévio das classes de alvos, a fim de classificar a imagem nas classes de interesse pré-fixadas pelo analista (MENESES et al., 2012). Realizou-se a segmentação das imagens, que 
consistiu em um procedimento adotado antes da fase de classificação supervisionada. Através desse procedimento, a imagem é dividida em regiões espectralmente homogêneas, um agrupamento de pixels que possuem características semelhantes (MOREIRA, 2001; BRITES et al., 2012).

No processo de classificação supervisionada, foram utilizadas as imagens falsa-cor com base nas seguintes composições RGB: 432 para as imagens do TM/Landsat-5; e 543 para as imagens do OLI/Landsat8. Ou seja, foram utilizados os comprimentos de ondas do infravermelho próximo, do vermelho e do verde e associados ao canal RGB, respectivamente. Na etapa de obtenção das amostras, isto é, treinamento supervisionado foram definidas seis classes, a saber: Agricultura Irrigada, Agropecuária-Solo Exposto, Área Construída, Afloramento Rochoso, Cobertura Vegetal e Corpos D’Água.

Nesse sentido, utilizaram-se para treinamento e posterior classificação das imagens dos anos de 2007 e 2018, os polígonos gerados nas segmentações feitas no software SPRING 5.4.3 pelo método Crescimento de Regiões, e posteriormente a classificação supervisionada com o método Bhattacharyya, também realizada no SPRING. Após a realização dessas etapas, foram gerados os dois mapas temáticos referentes aos anos de 2007 e 2018 que foram exportados para o software QGIS 3.10.8 e convertidos para formatos vetorial e posteriormente editados. Com os mapas no formato vetorial foi possível manipular a tabela de atributos na calculadora de campo do QGIS, realizar o cálculo da área de cada classe gerada e sua respectiva porcentagem em relação à área total.

\section{Validação da classificação}

Para validar a classificação supervisionada, utilizou-se o Plugin ACATAMA, complemento de validação de mapas no QGIS 3.10.8, geraram-se 60 pontos amostrais, distribuídos aleatoriamente, sendo 10 para cada classe, sobre a classificação resultante do método Bhattacharayya correspondente ano de 2018, utilizado como mapa referência para realizar a validação do mapeamento. Os pontos gerados foram transformados em um arquivo vetorial e exportado para o aplicativo Google Earth Pro instalado no celular smartphone para facilitar a localização dos pontos em campo. Esse aparelho também foi utilizado para registrar as classes mapeadas. Utilizou-se de planilha para a caracterização das classes, aparelho receptor de GPS (Garmin Etrex10) e mapa resultante da classificação do ano 2018. Para a Acurácia da classificação, utilizou-se como método a Exatidão Global, que varia em uma escala de 0 a 100\%, calculada a partir da matriz de confusão ou de erros (MENESES et al., 2012).

\section{Mapeamento dos Poços Tubulares}

A coleta dos dados dos poços tubulares ocorreu a partir de visitas a campo nas propriedades agrícolas e órgãos públicos. Definimos como prioridade, a área correspondente a Sub-bacia do Riacho Baixão de Gabriel, visto que é onde está concentrada a maioria dos poços em atividade. Foram registradas as coordenadas UTM, assim como dados de vazão e profundidade de 75 poços tubulares identificados no campo. Além desses foram utilizados dados de 98 poços tubulares existentes na área de estudo, segundo informações compiladas da CERB/SIAGAS. Os procedimentos metodológicos adotados neste trabalho estão 
sintetizados em um fluxograma, Figura 2.

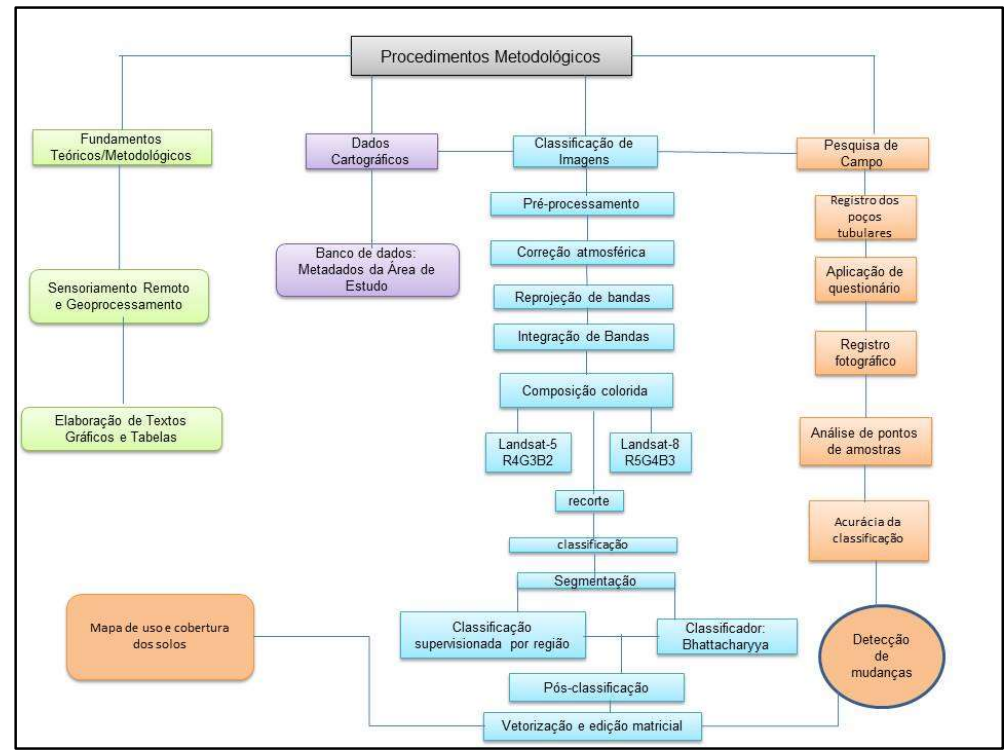

Figura 2: Fluxograma das etapas metodológicas.

\section{RESULTADOS E DISCUSSÃO}

A classificação final resultou nos mapas de Uso e Cobertura das Terras para os anos de 2007 e 2018 (Figura 3), os quais serviram de base para analisar as mudanças ocorridas no município de São Gabriel ao longo do período estudado.

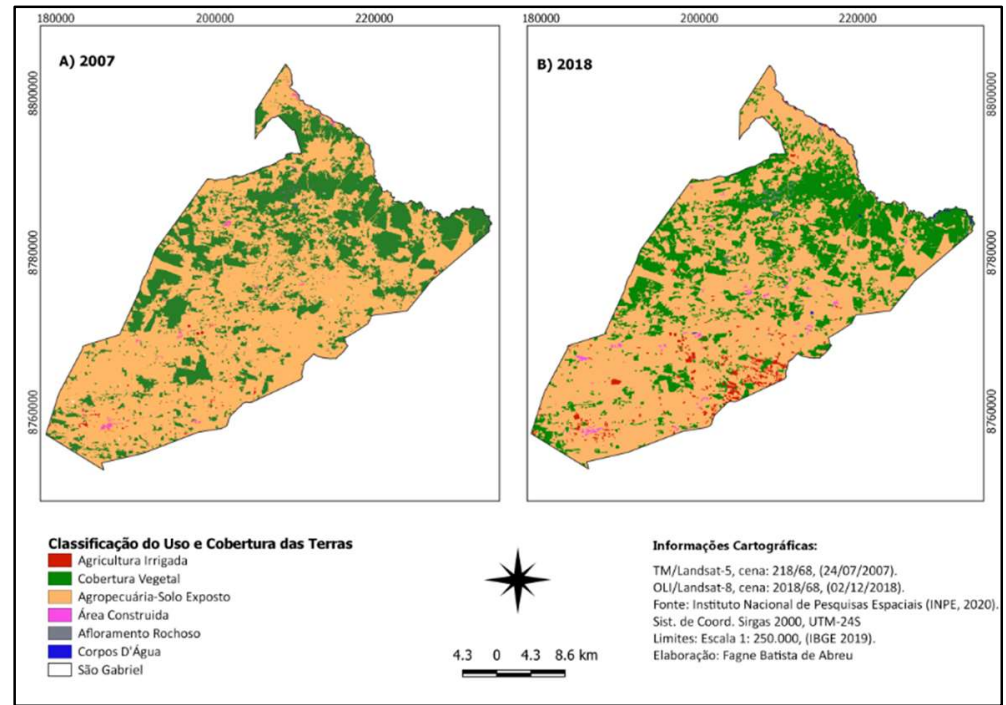

Figura 3: Mapa de Uso e Cobertura das Terras, 2007 e 2018.

Os resultados da classificação final também permitiram quantificar as classes mapeadas, suas respectivas áreas e percentuais de mudanças (Tabela 1). Diante da dinâmica local observada nos mapas e nos trabalhos de campo, nota-se que algumas classes apresentaram mudanças mínimas para o período como a classe Corpos D'água 0,08\%, Afloramento Rochoso 0,25\% e Área Construída 0,1\%, enquanto outras, as mudanças foram mais significativas, a exemplo da classe Agricultura Irrigada que aumentou 1,6\%, seguida da classe Agropecuária Solo-Exposto que reduziu 1,1\% e da Cobertura Vegetal houve redução de 0,8\%.

Destaca-se pelo tamanho da área que ocupa nessa classificação a Agropecuária-Solo Exposto, que 
mesmo apresentando uma redução no período analisado, ainda corresponde a $778 \mathrm{~km}^{2}$, ou seja, $67,9 \%$ da área total. Segundo Oliveira (2015), a agropecuária é a atividade econômica de maior expressão no município de São Gabriel e está distribuída em quase todo o território. As lavouras temporárias de milho e mamona são atualmente as mais importantes e ao longo dos últimos anos junto com as de feijão que diminui a cada ano, respondem pela maior parte das terras cultivadas. Isso explica em parte, a grande extensão identificada dessa classe nesse mapeamento.

Tabela 1: Classes mapeadas, suas respectivas áreas e percentuais de mudanças.

\begin{tabular}{l|llll|l}
\hline Uso e cobertura das terras & $\mathbf{2 0 0 7} \mathbf{~ k m}^{\mathbf{2}}$ & $\mathbf{2 0 0 7 \%}$ & $\mathbf{2 0 1 8} \mathbf{~ k m}^{\mathbf{2}}$ & $\mathbf{2 0 1 8} \mathbf{~}$ & Mudanças (\%) \\
\hline Corpos D'água & 0,72 & 0,06 & 1,6 & 0,14 & 0,08 \\
Afloramento Rochoso & 1,6 & 0,14 & 4,4 & 0,39 & 0,25 \\
Agricultura Irrigada & 4,0 & 0,35 & 22 & 2 & 1,65 \\
Área Construída & 4,6 & 0,4 & 5,7 & 0,5 & 0,1 \\
Cobertura Vegetal & 339 & 29,6 & 330 & 28,8 & $-0,8$ \\
Agropecuária-Solo Exposto & 791 & 69 & 778 & 67,9 & $-1,1$ \\
\hline Total & 1.146 & $100 \%$ & 1.146 & $100 \%$ & $3,98 \%$ \\
\hline
\end{tabular}

Em 2007, a Agropecuária-Solo Exposto ocupava uma área de $791 \mathrm{~km}^{2}$, o equivalente a $69 \%$ do município. Essa classe agrupa áreas de agricultura de sequeiro, pastagem, área preparada para o plantio e pós-colheita, além de solo exposto correspondente às áreas que no momento da passagem do satélite encontravam-se desnudas, sem nenhum tipo de cobertura vegetal. Predominavam os cultivos agrícolas de sequeiro e as pastagens para a pecuária com destaque para a caprinocultura desenvolvida na própria caatinga, marcante às margens do rio Jacaré na porção norte do município. Nessa época, a ação antrópica já se dava de forma bastante acentuada, principalmente nas proximidades do centro urbano e ao longo dos principais cursos d'água. Para Silva (2005), essa configuração se dá desde meados da década de 1970, auge da produção agrícola na região de Irecê, favorecido pelo relevo suave, solos ricos em nutrientes associados às rochas carbonáticas que possibilitaram a implantação de culturas agrícolas como feijão, milho e mamona.

Outra classe que merece destaque no que tange ao tamanho de área ocupada, em relação às demais é a Cobertura Vegetal, que em 2007 ocupava $339 \mathrm{~km}^{2}$ da área total, correspondente a 29,6\%, concentrada principalmente nas porções norte e nordeste do município, incluindo parte da APA Gruta dos Brejões. É uma vegetação de caatinga remanescente, arbustiva densa, que ocupa áreas que ainda não sofreram a intensa ação antrópica (SILVA, 2005), possivelmente manteve-se conservada pela sua localização. Nessas áreas, os solos são menos férteis, apresentam pouca profundidade e estão em terrenos declivosos, dificultando os processos de mecanização agrícola. Em outras porções da área de estudo, esse mapeamento mostrou a existência de uma caatinga espinhosa e com folhas pequenas, caracterizada pela perda da folhagem no período de estiagem (desciduidade), são formações espaçadas e intercaladas entre áreas de expansão das atividades agropecuárias.

A classe Área Construída inclui a mancha urbana da sede do município de São Gabriel, dos distritos de Besouro e Gameleira do Jacaré e mais nove localidades, Baixão dos Honoratos, Baraúna, Caroazal, Curralinho, Gabrielzinho, Jurema, Lagoinha, Pitial e Variante. Em 2007, essa classe ocupava 4,6 km² de extensão, o que corresponde a 0,4\% da área municipal.

A classe Agricultura Irrigada aumentou 1,65\% destacando-se como uma das classes que apresentou 
o maior crescimento entre o período de 2007 e 2018. Em 2007, essa classe aparecia ocupando uma área de $4 \mathrm{~km}^{2}$, ou seja, 0,35\% do município, podendo inferir que era uma atividade incipiente. Todavia, segundo Oliveira (2015), já demonstrava o potencial existente para a agricultura irrigada, principalmente por meio da captação de água nos lençóis freáticos, devido os cursos d’água apresentar regimes temporários não possibilitando o aproveitamento para a agricultura. As poucas áreas de irrigação mapeadas em 2007 se desenvolveram sobre solos de origem cárstica, dentro da Sub-bacia do Riacho Baixão de Gabriel, os Cambissolos. Esses solos possuem matiz avermelhada, textura argilosa ou muito argilosa, rasos a moderadamente profundos e bem a moderadamente drenados e apresentam alta fertilidade natural (SILVA, 2005). Essas características, associadas a um relevo que favorece o uso de máquinas agrícolas, fazem desses solos os mais cultivados no município, e uma promessa para o desenvolvimento dos cultivos irrigados (Figura 4).

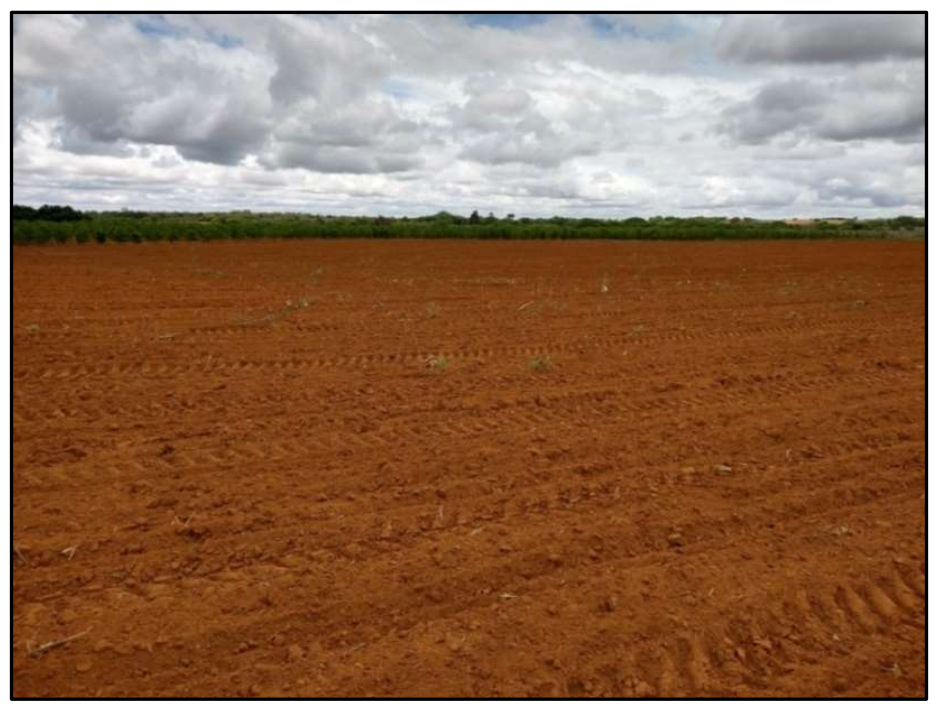

Figura 4: Cambissolo preparado para o plantio.

A classe Afloramento Rochoso apresentava em 2007 uma área de 1,6 km², isto é 0,14\% da área municipal. São formações rochosas do Grupo Una/Bambuí, do Neoproterozóico, com predomínios de calcarenítos intraclásticos com laminação cruzada (GUERRA, 1986). Este substrato rochoso apresenta coloração cinza-escura com intensos processos de carstificação que esculpem sumidouros e cavernas principalmente no centro e norte do município.

Para a classe Corpos D’Água, identificou-se uma área de $0,72 \mathrm{~km}^{2}$, ou $0,06 \%$, no ano de 2007 . Isso se deve principalmente aos baixos índices pluviométricos das últimas décadas que tem afetado o regime hidrológico dos cursos d'água que apresentam regimes temporários e efêmeros. Observou-se uma oscilação nos índices pluviométricos nos últimos anos. Os anos de 2001, 2003, 2007, 2012, 2014,2015 e 2017 apresentaram baixos volumes de chuvas, menores que $400 \mathrm{~mm}$ (Figura 5). Além disso, o desmatamento das margens e nascentes dos rios e riachos tem intensificado o assoreamento dos canais, provocando o desaparecimento dos corpos d'água. Essas alternâncias de períodos de baixas precipitações, e alguns anos com maior volume de chuvas, é uma característica marcante dos ambientes semiárido. Essas características refletem na configuração da rede de drenagem da área, pouco densa, que prevalecem pequenos riachos efêmeros e intermitentes, o que dificulta a detecção desses corpos D'água pelo sensor, cuja resolução 
espacial foi de $30 \mathrm{~m}$, sendo registrados apenas os locais de acumulação de água em alguns trechos do Rio Jacaré, por serem áreas relativamente mais extensas.

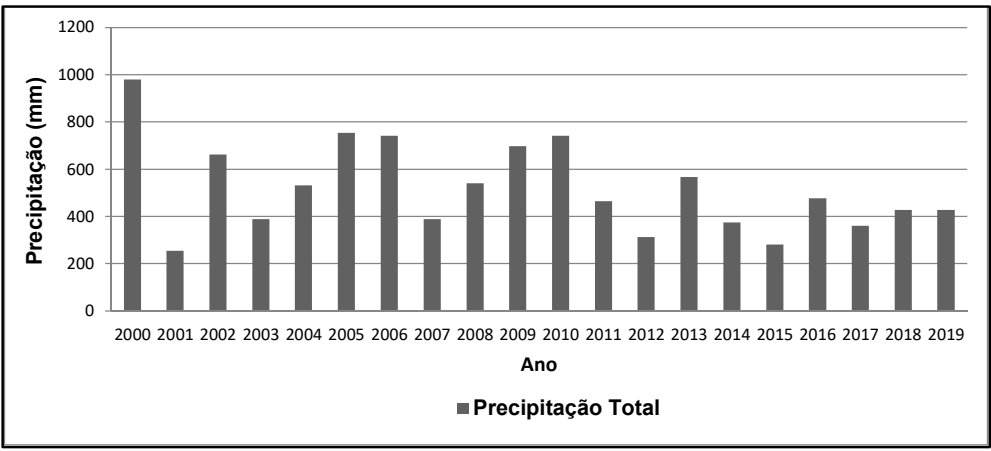

Figura 5: Precipitação total anual do município de São Gabriel (2000-2019).

No mapa de Uso e cobertura dos solos de 2018, a classe Corpos D'água aumentou a sua área para $1,6 \mathrm{~km}^{2}$, a classe Afloramento Rochoso aumentou para 4,4 km², Agricultura Irrigada com a expansão mais expressiva entre todas as classes alcançou $20 \mathrm{~km}^{2}$, Área Construída teve um crescimento para $5,7 \mathrm{~km}^{2}$. As classes de Cobertura Vegetal e a de Agropecuária Solo-Exposto foram as únicas que apresentaram retração da área, de 339 km² em 2007 para 330 km² em 2018, e 791 km² em 2007 para 778 km² em 2018, respectivamente.

A classe Agropecuária/Solo Exposto em 2018 teve sua extensão reduzida para 778 km², ou seja, 1,1\% de retração. Essa mudança pode ser justificada pela conversão de áreas tradicionalmente utilizadas para agricultura de sequeiro em atividades agrícolas irrigadas. Os trabalhos de campo possibilitaram observar que essa conversão está relacionada às baixas precipitações dos últimos anos, essa irregularidade das chuvas tem levado os agricultores a buscarem alternativas para diminuírem a dependência do regime de chuvas no cultivo de produtos como milho e mamona. Diante dessa deficiência hídrica ou instabilidade pluviométrica, faz-se necessário o uso da irrigação, utilizando a água subterrânea, pois essa prática possivelmente diminui as perdas totais dos cultivos agrícolas, possibilitando maiores produtividades, e permite o plantio de novas culturas (Figura 6).

Em 2018, a classe Cobertura Vegetal passou a ocupar uma área de $330 \mathrm{~km}^{2}, 28,8 \%$ da área municipal. Apesar desse mapeamento revelar uma superfície de $28,8 \%$ de cobertura de caatinga arbórea/arbustiva, a mesma encontra-se bastante fragmentada, permanecendo remanescente de caatinga em algumas áreas. Os estudos de campo e a interpretação das imagens mostraram que esse percentual de decréscimo de $0,8 \%$ corresponde a perda da cobertura vegetal para a agricultura de sequeiro e pastagem. As mudanças ocorridas na Cobertura Vegetal na porção norte do município se destacam, principalmente nas proximidades da comunidade de Curralinho e Manga, pois houve o avanço da pecuária em direção às margens da Vereda do Rio Jacaré. Nessas áreas, percebe-se a expansão de processos erosivos ao longo do vale, onde o desmatamento é bastante intenso, e as condições naturais como a declividade do relevo, os solos arenosos e pedregosos, a concentração das chuvas em poucos meses do ano (de forma torrencial) e a ausência de vegetação natural ou antrópica facilitam a erosão hídrica. As encostas encontram-se bastante erodidas, com formação de sulcos, ravinas e voçorocas (Figura 7), consequentemente provoca o assoreamento do canal do 
rio.

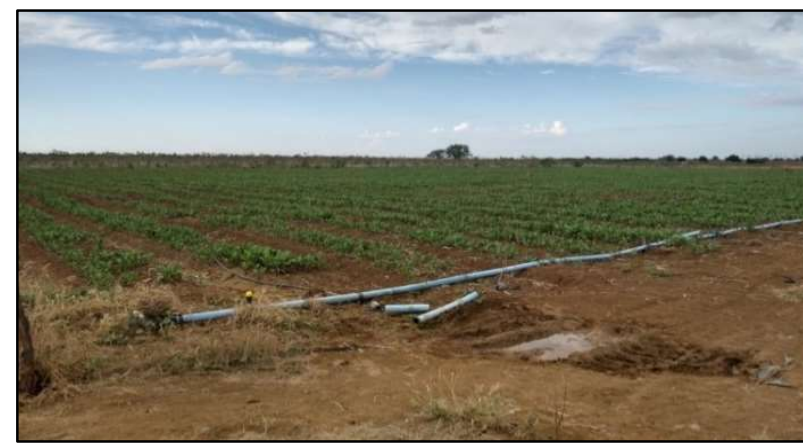

Figura 6: Cultivo de Beterraba no Distrito de Besouro.

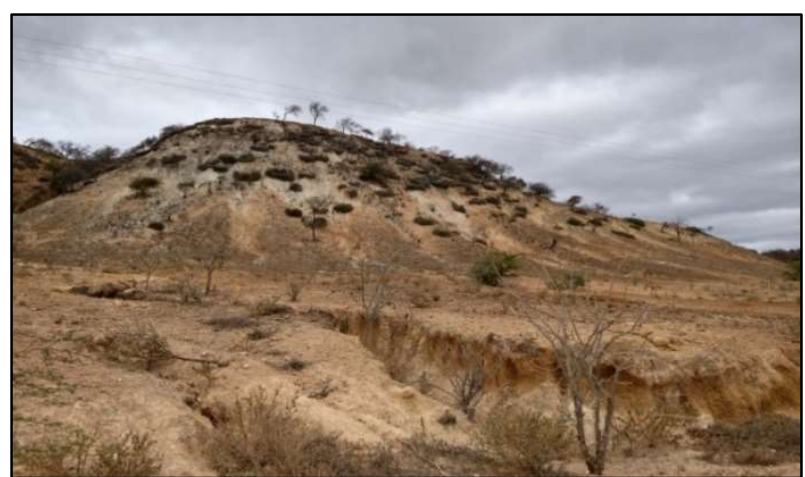

Figura 7: Processo erosivo avançado, extremo norte do município.

Esse dado demonstra que o uso intensivo dos solos por agricultura e pastagens tem provocado um impacto significativo na caatinga. Como já destacado por Machado (2004), as explorações desenfreadas da vegetação nativa no município de São Gabriel, consequências das monoculturas, geraram inúmeros problemas ambientais, desmatamento da caatinga, exposição de encostas, supressão de matas ciliares e assoreamento de rios e riachos. No que se refere ao uso e cobertura das terras, a agricultura provocou a supressão da vegetação primária de tal modo que hoje se encontra recolhida a pequenos redutos em áreas de pouco interesse econômico no centro-norte e extremo norte da área municipal. Para Flores (2011), a manutenção da vegetação de caatinga no ambiente semiárido contribui para atenuar os efeitos erosivos e a lixiviação dos solos, promovendo a regularização do fluxo hídrico e redução do assoreamento dos fluxos d'água. Nessa pesquisa, percebeu-se que a forma mais comum de erosão presente na área de estudo é a perda da camada superficial do solo pelo aumento da erosão pluvial (erosão laminar), consequência da supressão da vegetação.

A classe Área Construída que inclui a mancha urbana da sede do município de São Gabriel, dois distritos e nove povoados, em 2018 apresentou uma área de $5,7 \mathrm{~km}^{2}$, ou seja, houve um aumento de $0,1 \%$ em relação a 2007. O aumento dessa classe está relacionado a uma pequena expansão de novos bairros na sede do município, devido às melhorias de infraestrutura, como calçamentos e algumas pavimentações, construção de creches, e uma melhor distribuição espacial dos postos de saúde.

A classe Afloramento Rochoso verificou-se um aumento, de 1,6 km² em 2007 para 4,4 km² em 2018, o que corresponde a 0,39\% da área do município. Esse aumento, como verificado em campo, está diretamente relacionado ao desmatamento em áreas com predomínio da caprinocultura para ampliação de pastagens. Essa exposição das rochas também está relacionada ao intenso intemperismo físico e a erosão superficial, que provocam a fragmentação e exposição das rochas nas camadas superficiais (Figura 8).

Outra classe que merece destaque nessa classificação é a Agricultura Irrigada que apresentou um crescimento de 1,65\% entre, 2007 e 2018. Tal classe passou a ocupar áreas de Agropecuária/Solo Exposto, em propriedades, onde se praticava a agricultura de sequeiro, e passaram a utilizar a irrigação, ou seja, o avanço das áreas de cultivos irrigados deu-se em áreas já degradadas. Contudo, ainda é reduzida a extensão das áreas cultivadas. Observou-se que a expansão da agricultura irrigada ocorreu no planalto cárstico de São 
Gabriel (Figura 9), área de grande interesse econômico e hidrogeológico porque, na maioria das vezes, possui solos agricultáveis de qualidade e valiosas reservas de água no subsolo (SILVA, 2008). O aumento das áreas irrigadas nos últimos anos é uma possibilidade de sobrevivência das atividades agrícolas no município, devido à queda na produção agrícola de sequeiro (OLIVEIRA, 2009).

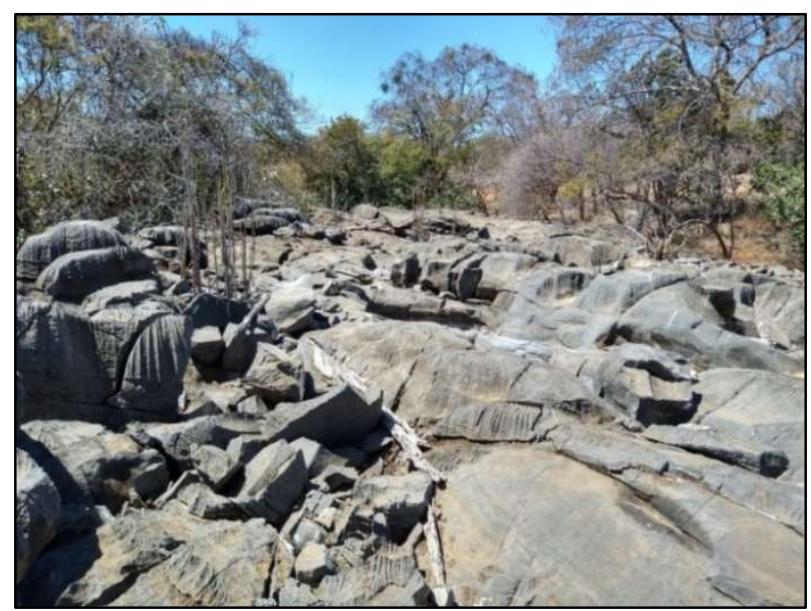

Figura 8: Afloramento de rochas carbonáticas, localidade de Caroazal.

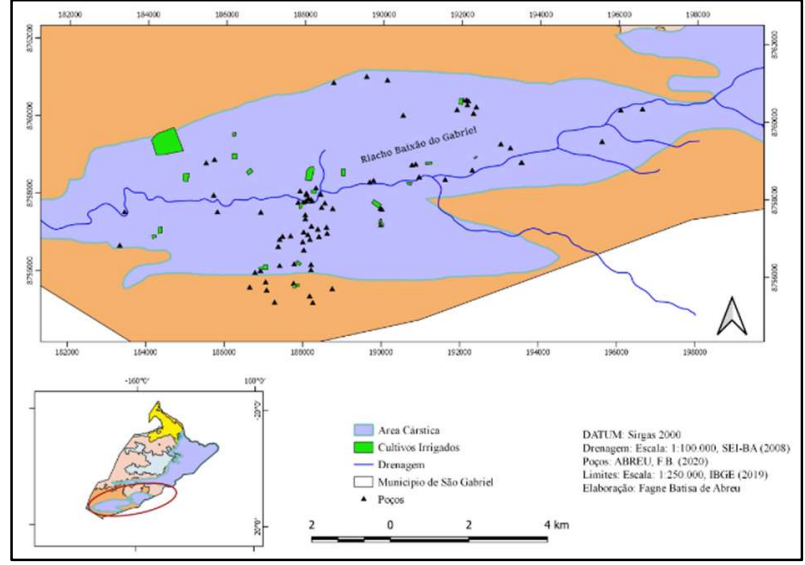

Figura 9: Poços coletados na pesquisa de campo sobreposto ao carste na Sub-bacia do Riacho Baixão.

Nesse estudo, observou-se uma concentração dos poços georreferenciados na Sub-bacia do Baixão de Gabriel, esse dado corrobora com o mapa de classes de 2018, assim como os dados de mudanças da classe agricultura irrigada. Essa classe expandiu 1,65\% entre os anos de 2007 e 2018, os poços mapeados totalizaram 71 entre os anos de 2001 a 2020, ou seja, observou-se que tanto o aumento da classe agricultura irrigada como o aumento na perfuração de poços tubulares no período analisado apresentaram uma concentração nos domínios cársticos da área de estudo (Figura 10). O planalto cárstico é uma unidade geomorfológica que se constitui numa chapada descontínua com altitudes que variam entre 600 a 800 metros, coincidente com as áreas do afloramento dos calcários do Grupo Una (GUERRA, 1986). Caracterizase por uma topografia levemente ondulada, com elevações suaves e sem a formação de escarpas (SILVA, 2005). Essas características favorecem a implantação da agricultura irrigada que, aliadas a existência de solos férteis, elevam o potencial agrícola na área de estudo (GUERRA, 1986).

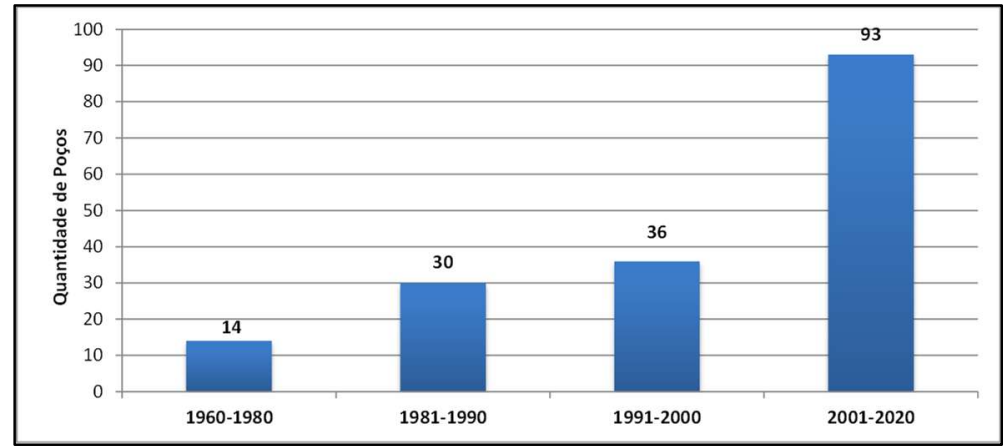

Figura 10: Poços distribuídos por período, município de São Gabriel-BA.

Diante disso, observa-se que mesmo apresentando ainda um crescimento incipiente, os dados dos mapas classificados e os percentuais de mudanças, apontam para um crescimento da área irrigada. A agricultura irrigada na área de estudo tende a aumentar, dependente necessariamente das águas 
subterrâneas, isto em função da irregular pluviosidade e da carência de outros mananciais (GUERRA, 1986; NEGRÃO, 1987). A hidrogeologia caracterizada por sedimentos cársticos, o relevo plano e os Cambissolo férteis demonstram grande potencial da área para os cultivos irrigados.

Todavia, o que preocupa são os danos ambientais que possam ocorrer associados a esse avanço na perfuração de poços tubulares, a maioria é perfurada sem um prévio estudo técnico da área, e sem o conhecimento preciso da hidrodinâmica do aquífero, posto que a localização dos poços é demarcada a partir do conhecimento popular. A falta de outorgas conjuntamente com a clandestinidade na perfuração de poços no município são fatores evidentes de superexploração das águas subterrâneas, isso vem sendo confirmado em depoimentos de usuários localizados na Sub-bacia do Baixão de Gabriel, que relatam perceber uma diminuição constante das vazões dos seus poços em momentos em que vários agricultores estão molhando seus cultivos, evidenciando possíveis conflitos, num futuro próximo, pelo uso da água subterrânea na área de estudo.

Outra preocupação diz respeito à contaminação das águas subterrâneas do aquífero cárstico na Subbacia do Baixão de Gabriel. A forte vocação agrícola da área, juntamente com esse aumento dos cultivos irrigados, possivelmente aumentará o uso de fertilizantes e defensivos agrícolas, potencializando a contaminação do solo e aquífero. Atualmente, o uso desses produtos ainda é pequeno, entretanto, com a possibilidade de expansão dos cultivos irrigados, esse tipo de contaminação pode se torna frequente na área. Guerra (1986) e Negrão (1987), enfatizam os aspectos da vulnerabilidade à contaminação do aquífero cárstico da área municipal, ou seja, a pouca profundidade e a sistemática de recarga através das formas de absorções abertas, como os sumidouros, fendas, dolinas, etc., em que as águas passam diretamente da superfície para a subsuperfície sem sofrer os efeitos da filtração natural comum nos terrenos sedimentares, tornam os cársticos dessa área extremamente vulneráveis aos contaminantes.

Considerando o quadro atual e a tendência de ampliação da agricultura irrigada na Sub-bacia do Riacho Baixão de Gabriel, possivelmente aumentará a exploração da água subterrânea por meio de poços tubulares, o que poderá acelerar o rebaixamento do nível freático, principalmente nos anos de baixas precipitações. Esse rebaixamento dos níveis freáticos cria-se espaços vazios no carste como condutos e cavernas, elevando os riscos de acidentes geotécnicos como as subsidências e colapsos nas camadas subsuperficiais.

Uma das últimas etapas da classificação de Uso e Cobertura das Terras é a validação dos resultados, a partir da qual se busca avaliar a acurácia da classificação. Diante do exposto, a validação da classificação supervisionada com uma Exatidão Global de 86,6\% mostrou-se a eficiência do método adotado, atendendo aos objetivos propostos nesse trabalho.

\section{CONCLUSÕES}

Nessa pesquisa o uso de dados de sensoriamento remoto e das técnicas de geoprocessamento mostraram-se importantes ferramentas para as análises de Uso e Cobertura das Terras. A pesquisa mapeou as mudanças ocorridas entre os anos de 2007 e 2018, os comportamentos de expansão ou supressão das 
classes mapeadas, impulsionadas por fatores naturais e socioeconômicos. Possibilitou verificar que a agricultura de sequeiro e as pastagens ainda configuram como sendo o principal meio de alteração da vegetação de caatinga, desencadeando uma degradação dos solos em uma escala acelerada, contribuindo para o aumento do escoamento superficial das águas e redução da capacidade de infiltração do solo, reduzindo a recarga do aquífero e aumentando os processos erosivos.

Assim, devem ser elaboradas medidas de gestão ambiental para o planejamento correto do uso dos recursos naturais no município de São Gabriel. Dentre algumas medidas efetivas que possam ser tomadas com parcerias entre o poder público municipal e agricultores locais, podem ser citadas a preservação de áreas naturais, ou seja, a proteção de remanescentes de vegetação de caatinga encontradas em algumas propriedades. No que se refere ao uso da água subterrânea nas atividades agrícolas irrigadas, apesar de ser uma atividade ainda incipiente, faz-se necessário um levantamento mais aprofundado da quantidade de poços tubulares em atividade.

Diante disso o uso das geotecnologias poderá auxiliar muito em ações de monitoramento e diagnóstico dos processos de uso dos recursos naturais na área de estudo, disponibilizando dados que possivelmente possam contribuir para um melhor planejamento da área municipal, visto que o uso de dados de sensoriamento remoto combinado com um SIG permite a compreensão de forma integrada da paisagem, seus aspectos naturais e antrópicos.

\section{REFERÊNCIAS}

BAHIA. Companhia Baiana de Pesquisa Mineral. Modelagem metalogenética espacial: estudo de caso na Bacia de Irecê. Salvador: CBPM, 2015.

BENEDETTI, A. C. P.. Análise espacial da evolução do uso e cobertura da terra na Sub-bacia hidrográfica do Arroio Arenal, Santa Maria-RS. Dissertação (Mestrado em Engenharia Florestal) - Universidade Federal de Santa Maria. Santa Maria, 2006.

BRITES, R. S.; BIAS, E. S.; ROSA, A. N. C. S.. Classificação por Regiões. In: MENESES, P. R.; ALMEIDA, T.. Introdução ao Processamento de Imagens de Sensoriamento Remoto. 2 ed. Brasília: UNB, 2012.

EMBRAPA. Empresa Brasileira de Pesquisas Agropecuárias. Sistema Brasileiro de Classificação de Solos. 5 ed. Brasília: EMBRAPA, 2018.

FLORES, P. M.. Análise multitemporal do avanço da fronteira agrícola no município de Barreiras: (1988-2011). Dissertação (Mestrado em Gestão Ambiental e Territorial) Universidade de Brasília, Brasília, 2011.

GUERRA, A. M.. Processos de Carstificação e Hidrogeologia do Grupo Bambuí na Região de Irecê - Bahia. Tese (Doutorado em Geociências) - Universidade de São Paulo, São Paulo, 1986.

IBGE. Instituto Brasileiro de Geografia e Estatística. Manual Técnico em Geociências: Manual de Uso da Terra. 3 ed. Rio de Janeiro, 2013.
MACHADO, C.. São Gabriel, memórias e lembranças. Irecê: Print Fox, 2004.

MENESES, P. R.; SANO, E. E.. Classificação pixel a pixel de imagens. In: MENESES, P. R.; ALMEIDA, T.. Introdução ao Processamento de imagens de sensoriamento remoto. 2 ed. Brasília: UNB, 2012.

MOREIRA, M. A.. Fundamentos do Sensoriamento Remoto e Metodologias de Aplicação. São Jose dos Campos, 2001.

NEPOMUCENO, M. Q.. Análise geossistêmica da região de Irecê-BA. Dissertação (Mestrado em Geografia) Universidade Federal da Bahia, Salvador, 2014.

NEGRÃO, F. I.. Caracterização Hidrogeoquímica e Vulnerabilidade do Sistema Hidrogeológico Cárstico da Região de Irecê, Bahia. Dissertação (Mestrado em Geociências) - Universidade de São Paulo, São Paulo, 1987.

OLIVEIRA, E. F.. Implicações da pluriatividade na produção do espaço agrário no município de São Gabriel-BA.

Dissertação (Mestrado em Geografia), Universidade Federal da Bahia, Salvador, 2015.

OLIVEIRA, C. N. N.. Análise Geoambiental da Bacia Hidrográfica do Rio Jacaré na Região de Irecê, com o uso do Sistema de Informações Geográficas (SIG). Dissertação (Mestrado em Engenharia Civil e Ambiental) - Universidade Estadual de Feira de Santana, Feira de Santana, 2009.

PEREIRA, J. P.; PEREIRA, L.. Terra dos Arcanjos. Historiografia da cidade de São Gabriel - BA. 2 ed. Irecê: Print Fox. 2013. 
PRADO, R. B.. Geotecnologias aplicadas à análise espaço temporal do uso e cobertura da terra e qualidade da água do reservatório de Barra Bonita, SP, como suporte à gestão de recursos hídricos. Tese (Doutorado em Engenharia) Universidade de São Paulo, São Paulo, 2004.

RAMOS, S. O.; ARAUJO, H. A.; LEAL, L. R. B.; LUZ, J. A. G.; DUTTON, A. R.. Variação temporal do nível freático do aquífero cárstico de Irecê - Bahia: contribuição para uso e gestão das águas subterrâneas no semiárido. Revista Brasileira de Geociências, Salvador, v.37, n.4, p.227-233, 2007.

ROCHA NETO, O.; FIDELES FILHO, J.; LACERDA, G. L. B.; BARBOSA, P. G.; SILVA, T. J. R. D.. Análise do uso e ocupação do solo no interior baiano através das geotecnologias: estudo de caso no município de São Gabriel. Revista Ibero Americana de Ciências Ambientais, v.11, n.5, p.652-663, 2020. DOI: http://doi.org/10. 6008/CBPC2179$\underline{6858.2020 .005 .0058}$
SEl. Superintendência de Estudos Econômicos e Sociais da Bahia. Tipologia Climática da Bahia. Escala 1: 2.000.000. Salvador: SEI, 1998.

SEI. Superintendência de Estudos Econômicos e Sociais da Bahia. Solos da Bahia. Escala 1: 6.500.000. Salvador: SEI, 2001.

SILVA, M. H.. Sistema de informações geográficas do aquífero cárstico da microrregião de Irecê, Bahia: subsídio para a gestão integrada dos recursos hídricos das bacias dos rios verde e jacaré. Dissertação (Mestrado em Geoquímica e Meio Ambiente) - Universidade Federal da Bahia, Salvador, 2005.

SILVA, A. B.. Hidrogeologia de meios Cársticos. In: FEITOSA, F. A. C.. Hidrogeologia: conceitos e aplicações. 3 ed. Rio de Janeiro: CPRM:LABHID, 2008.

TEIXEIRA, A. H. C.. Informações Agrometeorológicas do polo de Petrolina, PE/Juazeiro: 1963 a 2009. Petrolina: Embrapa Semiárido, 2010.

A CBPC - Companhia Brasileira de Produção Científica (CNPJ: 11.221.422/0001-03) detém os direitos materiais desta publicação. Os direitos referem-se à publicação do trabalho em qualquer parte do mundo, incluindo os direitos às renovaç̃oses, expansões e disseminações da contribuiç̃o, bem como outros direitos subsidiários. Todos os trabalhos publicados eletronicamente poderão posteriormente ser publicados em coletâneas impressas sob coordenação da Sustenere Publishing, da Companhia Brasileira de Produção Científica e seus parceiros autorizados. Os (as) autores (as) preservam os direitos autorais, mas não têm permissão para a publicação da contribuição em outro meio, impresso ou digital, em português ou em tradução. 